Focused on Showcasing Structural Integrity Research in India

\title{
Optimization of Vanadium Content for Achieving Higher Wear Resistance and Hardness in High Cr-V White Cast Irons for Ball Tube Mill Liner Application
}

\author{
Dhirendra Kumar, G. Jayaraman, M. Swamy, A. H. V. Pavan, Antony M. C. Harison \\ Corporate Research \& Development Division, BHEL, Hyderabad, India, 500093 \\ dkumar@bhel.in,jayaraman@bhel.in,smekala@bhel.in,pavanabv@bhel.in, barisonmo@bhel.in
}

\author{
A. N. Sudhakar \\ Heavy Power Equipment Plant, BHEL, Ramachandrapuram, Hyderabad, India, 502302 \\ ansudhakar@bhel.in
}

\begin{abstract}
The liner materials in coal fired tube mills are less promising due to lower combination of abrasion wear resistance, hardness and impact toughness properties, thus giving service life of 25,000 to 35,000 hours. In this study, focus was given to develop a high $\mathrm{Cr}-\mathrm{V}$ cast iron of high abrasion wear resistance with higher hardness and impact strength for ball tube mill liner application. The developed liner possesses high abrasive wear resistance and impact resistance simultaneously with expected service life of 40,000 to 50,000 hours. This grade was made using induction melting and sand casting method. The casting was heat treated in two stages to achieve higher abrasion wear resistance and mechanical properties. Various tests like chemical analysis, abrasion wear, hardness and impact tests were conducted on the above developed material. Abrasion wear test results show a low wear loss value (2.7 to $4.4 \mathrm{mg} / \mathrm{min})$. Hardness and impact tests show a high combination of hardness (57 to $64 \mathrm{HRC}$ ) and impact strength (44 to 57 $\mathrm{J} / \mathrm{cm}^{2}$ ). Prototype tube mill liners were manufactured and tested in a tube mill at 250MW site. Results obtained from site testing are also discussed in this study.
\end{abstract}

KEYwords. High $\mathrm{Cr}$ cast iron; High $\mathrm{Cr}-\mathrm{V}$ cast iron; Abrasion wear; Hardness; Impact strength.

\section{OPEN ACCESS}

Citation: Kumar, D., Jayaraman, G., Swamy, M., Pavan, A.H.V., Harison, A.M.C., Sudhakar, A. N., Study of microstructure, abrasion wear and mechanical properties of high $\mathrm{Cr}-\mathrm{V}$ white cast iron for ball tube mill liner application, Frattura ed Integrità Strutturale, 49 (2019) 507-514.

Received: 24.11 .2018

Accepted: 21.05 .2019

Published: 01.07.2019

Copyright: (C) 2019 This is an open access article under the terms of the CC-BY 4.0, which permits unrestricted use, distribution, and reproduction in any medium, provided the original author and source are credited.

\section{INTRODUCTION}

urning coal with higher efficiency has been a great need in coal pulverizing sector wherein coal is burnt like gas. Burning coal like gas reduces the $\mathrm{CO}_{2}$ emission by reduction of coal consumption. Coal is pulverized with the help of liner plates inside the mill. These plates are mostly made of high chromium cast irons (HCrCIs) and 
possess high hardness and wear resistance. $\mathrm{HCrCIs}$ have $\mathrm{M}_{7} \mathrm{C}_{3}$ carbide in their matrices which enables them to have high wear resistance property $[1,2]$. These cast irons have continuous distribution of rod-like $\mathrm{M}_{7} \mathrm{C}_{3}$ carbide in their respective matrices. The continuous distribution of $\mathrm{M}_{7} \mathrm{C}_{3}$ carbide makes their toughness lower. In order to improve their toughness, the morphology of carbides can be modified to chunk-like or even granular [3]. So, with discontinuous distribution of $\mathrm{M}_{7} \mathrm{C}_{3}$ carbide, a high chromium cast iron would be quite promising in wearing parts of machines in many industries like coal pulverizes. The demand of higher wear resistant material in coal pulverizing sector has always been encouraging to reduce the dwell time to the great extent. The need 'to eliminate frequent shutdown of tube mill for replacement of worn out and/or broken liners and loss in terms of power productivity' have encouraged to develop candidate alloys which provide superior abrasive wear resistance along with adequate toughness $[4,5]$. The addition of strong carbide-forming elements, such as vanadium, tungsten, niobium and titanium, improves the mechanical properties of high chromium white irons [6]. Vanadium can form vanadium carbide (VC) with Vickers hardness of HV2800 which is much harder than that of $\mathrm{M}_{7} \mathrm{C}_{3}$ with Vickers hardness, HV 1200 1800 in high chromium cast iron [7]. The globular morphology of VC reduces splitting to matrix and enables to get superior toughness. The microstructure of high chromium iron becomes finer with vanadium addition. With good solubility in eutectic $\mathrm{M}_{7} \mathrm{C}_{3}$ carbides and austenite, vanadium influences the transformation of austenite in high chromium cast iron. Vanadium content favors precipitation of dispersive secondary carbides of VC type in austenite which is favorable for martensitic transformation $[8,9,10]$. With an increase in vanadium content, the impact toughness increases, while hardness decreases and thereby relative wear resistance improves [7]. Therefore, influence of vanadium on microstructure, hardness and impact strength and wear properties was studied in this work to develop a high chromium-vanadium cast iron ( $\mathrm{HCrVCI})$ material for the tube mill liner application.

\section{EXPERIMENTAL PROCEDURE}

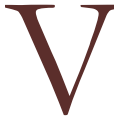

arious grades of $\mathrm{HCrCI}$ blocks with varying weight percentages of vanadium were cast using induction melting and die casting method. $\mathrm{HCrCI}$ grade, NFA 32.401 or $\mathrm{FB} \mathrm{Cr} 26 \mathrm{MoNi}$ with $0.00 \mathrm{wt} \%$ vanadium was considered as base material. The compositions of cast iron grades were analyzed through Spark Emission Spectroscopy (SES) method using Spectrax M5 machine. The cast iron blocks were hardened and tempered in two stages. Subsequent to this, Ultrasonic Testing (UT) was carried out on them to detect internal defects, if any. Samples were prepared from the casting blocks for microstructure evaluation, phase characterization, hardness, impact value and wear properties evaluation. Charpy un-notched impact test samples were prepared with dimensions as, Length: $10 \mathrm{~mm}$, Width: $10 \mathrm{~mm}$ and Height: $55 \mathrm{~mm}$. Abrasion wear test samples were prepared with dimensions as, Length: $25^{+0.0 /-0.2} \mathrm{~mm}$, Width: $6 \mathrm{~mm}$ and Height: $75 \mathrm{~mm}$. The samples for metallographic examination were polished for obtaining extremely good surface finish. The polished samples were etched chemically using Villela's etchant for 40 seconds each. The microstructures were analyzed through optical microscopy method. The etched samples were observed for features pertaining to morphology of grains and precipitates under Leica DMI $5000 \mathrm{M}$ inverted metallurgical microscope using the bright field method. The samples were further examined under "Zeiss Supra ${ }^{\circledR} 55$ VP make Field Emission Scanning Electron Microscope (FESEM) with compatible Energy Dispersive X-ray Spectroscopy (EDS) system to reveal morphologies present in the matrices. Hardness test with $10 \mathrm{~kg}$ load and 15 seconds dwell time was carried out on the surface of the samples from all cast iron grades using Shimadzu-HSV-30 hardness tester. Impact test was carried out on charpy un-notched test samples. The machine used for the impact test is IFFECT TECHNOLOGY, INC make Dynatup, Model 500. The working range of the machine as per the ASTM-E-23 is 25J to 286.4J. The wear test experiment was carried out as per the ASTM G 65. Abrasion wear test setup and schematic diagram of test apparatus is shown in Fig. 1. The samples for wear test were cleaned with methanol and dried. The specimens were weighed to the nearest $0.0001 \mathrm{~g}$. Each specimen was fixed securely in the holder and erodent (quartz sand; size: $180 \mu \mathrm{m}$ to $250 \mu \mathrm{m}$ ) was poured in the hopper. A load of $80 \mathrm{~N}$ was applied to the specimen against the wheel. The applied force was measured accurately by means of a spring scale which was hooked around the specimen and pulled back to lift the specimen away from the wheel. Revolution was set to $200 \mathrm{rpm}$. The erodent flow rate through the nozzles was approximately $330 \mathrm{~g} / \mathrm{min}$. The dwell time between the two tests was considered as 40 minutes. The each test was run for 15 minutes. Each time, the specimen was removed and reweighed to the nearest $0.0001 \mathrm{~g}$. Using the $\mathrm{HCrCI}$ Grade, FB Cr26MoNi with 0.50 wt. \% vanadium, few prototype liners were manufactured and installed in a coal pulverizing tube mill at an identified site along with freshly installed HCrCI Grade, FB Cr26MoNi liners for their comparative wear study and service life evaluation. 


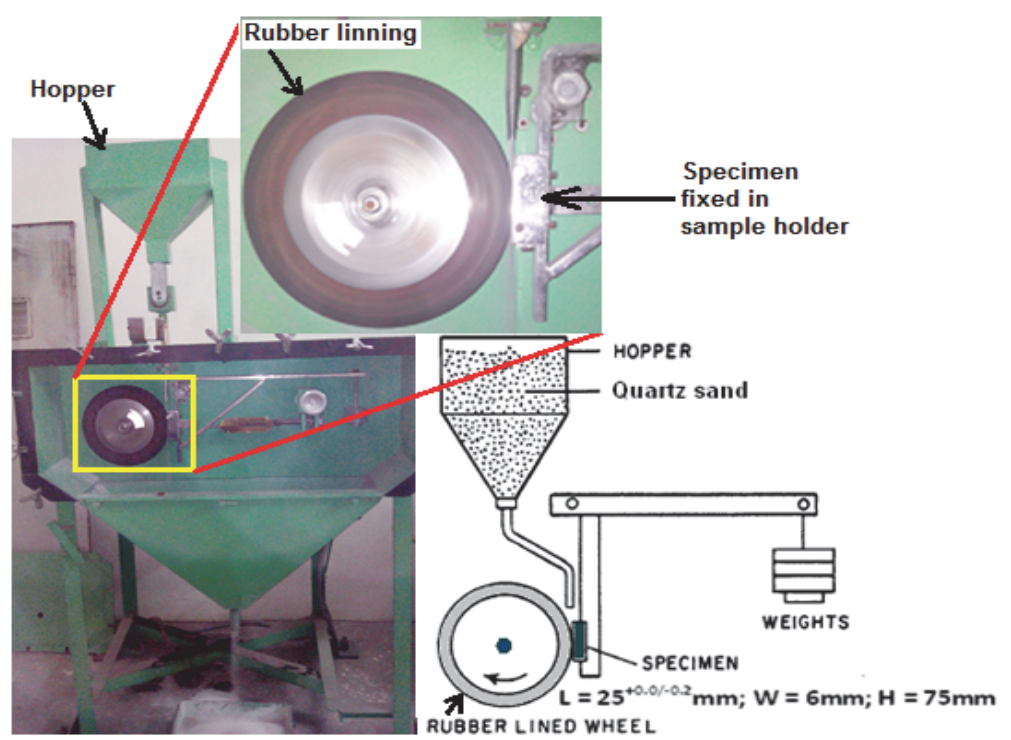

Figure 1: Abrasion wear testing setup and schematic diagram of test apparatus

\section{RESULT AND DISCUSSION}

\section{Chemical analysis}

fter successful casting, the chemical compositions of cast $\mathrm{HCrCI}$ and $\mathrm{HCrVCI}$ grades were analyzed and they were found within the range. Tab. 1 describes the compositions achieved for the various grades of cast irons. All 1 castings were hardened at $960^{\circ} \mathrm{C}$ for 10 hours and tempered at $295^{\circ} \mathrm{C}$ for 7 hours. Through ultrasonic testing (UT), all cast iron blocks were confirmed with good homogeneity.

\begin{tabular}{cccccccccccc}
\hline Grade of cast iron & \multicolumn{1}{c}{$\mathrm{C}$} & $\mathrm{Si}$ & $\mathrm{Mn}$ & $\mathrm{Ni}$ & $\mathrm{Mo}$ & $\mathrm{S}$ & $\mathrm{P}$ & $\mathrm{Cr}$ & $\mathrm{Cu}$ & $\mathrm{V}$ & $\mathrm{Fe}$ \\
FB Cr26MoNi & 2.69 & 0.99 & 0.99 & 0.21 & 0.29 & 0.05 & 0.04 & 25.09 & 0.30 & $\mathrm{Nil}$ & Bal. \\
FB Cr26MoNi +0.25V & 2.75 & 0.95 & 0.89 & 0.36 & 0.21 & 0.09 & 0.05 & 25.20 & 0.29 & 0.29 & Bal. \\
FB Cr26MoNi +0.5V & 2.74 & 0.80 & 0.99 & 0.35 & 0.39 & 0.05 & 0.04 & 24.99 & 0.39 & 0.53 & Bal. \\
FB Cr26MoNi +1.0V & 2.68 & 0.90 & 0.93 & 0.19 & 0.29 & 0.05 & 0.05 & 24.96 & 0.29 & 1.01 & Bal. \\
FB Cr26MoNi +2.0V & 2.69 & 0.72 & 1.02 & 0.22 & 0.30 & 0.03 & 0.04 & 24.99 & 0.35 & 2.03 & Bal. \\
FB Cr26MoNi +3.0V & 2.70 & 0.90 & 1.00 & 0.29 & 0.35 & 0.05 & 0.05 & 24.80 & 0.20 & 3.01 & Bal. \\
FB Cr26MoNi +4.0V & 2.58 & 0.89 & 1.05 & 0.22 & 0.29 & 0.05 & 0.05 & 25.02 & 0.29 & 4.02 & Bal. \\
FB Cr26MoNi +5.0V & 2.51 & 0.91 & 1.01 & 0.19 & 0.21 & 0.05 & 0.04 & 24.99 & 0.25 & 5.03 & Bal. \\
FB Cr26MoNi +6.0V & 2.50 & 0.80 & 1.10 & 0.20 & 0.41 & 0.05 & 0.04 & 25.10 & 0.19 & 6.00 & Bal. \\
FB Cr26MoNi +7.0V & 2.69 & 0.81 & 0.95 & 0.22 & 0.20 & 0.05 & 0.05 & 24.85 & 0.15 & 7.02 & Bal. \\
FB Cr26MoNi +8.0V & 2.70 & 0.80 & 0.90 & 0.21 & 0.29 & 0.04 & 0.04 & 24.90 & 0.20 & 8.01 & Bal. \\
\hline
\end{tabular}

Table 1: Compositions of the various grades of $\mathrm{HCrCIs}$ with varying vanadium content

\section{Microscopic examination}

The HCrVCI grade, FB Cr26MoNi+0.5V has achieved the best combination of hardness and impact strength which are discussed in the later stage. Therefore, the microstructures of base material (FB Cr26MoNi) and developed material (FB $\mathrm{Cr} 26 \mathrm{MoNi}+0.5 \mathrm{~V}$ ) were exclusively examined. Microstructure of FB Cr26MoNi material in Fig. 2: A) resembles coarse eutectic interdendritic rod-like continuous $\mathrm{M}_{7} \mathrm{C}_{3}$ carbides network in the gray tempered martensite matrix. Microstructure 
of FB Cr26MoNi+0.5V material in Fig. 2: B) shows fine globular MC type carbides and chunk like $\mathrm{M}_{7} \mathrm{C}_{3}$ carbides more uniformly distributed in the martensite structure which is reported to contribute better combination of hardness and impact strength. During eutectic solidification of $\mathrm{HCrCI}$ with vanadium addition, eutectic colonies diameter, ' $\mathrm{d}_{\mathrm{e}}$ ' is directly proportional to eutectic transition temperature range, ' $\Delta \mathrm{T}_{\mathrm{E}}$ '. This can be expressed as Eqn. (1) [15]:

$$
d_{e} \propto \Delta T_{E}
$$

Vanadium is found to narrow the eutectic transition temperature range and hence, refines the microstructure. Globular and chunk like uniform carbides precipitates distribution in the matrix of martensite is highly favorable for stabilizing the microstructure and imparting a better combination of higher hardness and impact toughness properties. Therefore, morphology of FB Cr26MoNi+0.5V cast iron is more suitable for tube mill liner application.
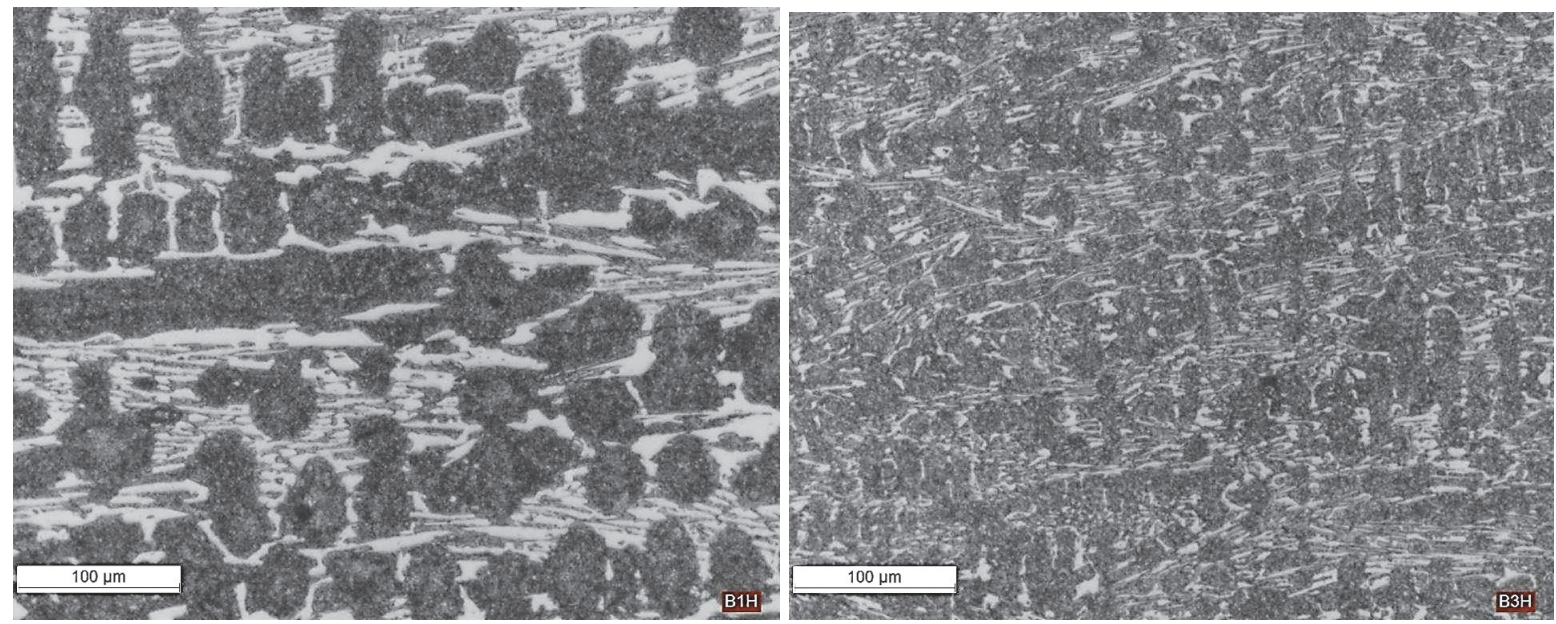

Figure 2: A) Microstructure of $\mathrm{HCrCI}$ grade, FB Cr26MoNi at 200X magnification and B) Microstructure of HCrVCI grade, FB $\mathrm{Cr} 26 \mathrm{MoNi}+0.5 \mathrm{~V}$ at $200 \mathrm{X}$ magnification.

\section{Field emission scanning electron microscopic analysis}

After microstructure evaluation, the high chromium cast iron (FB Cr26MoNi) and high chromium-vanadium cast iron (FB Cr26MoNi+0.5V) materials were examined under Field Emission Scanning Electron Microscope. FESEM images and EDS spectrums shown in Fig. 3: A) confirm the rod-like $\mathrm{M}_{7} \mathrm{C}_{3}$ carbide as chromium carbides in the continuous carbide network in the matrix of FB Cr26MoNi material and Fig. 3: B) \& C) confirm the globular MC type carbide as vanadium carbide and modified chunk like $\mathrm{M}_{7} \mathrm{C}_{3}$ type carbide as chromium carbide distribution with vanadium content in the matrix of $\mathrm{FB} \mathrm{Cr} 26 \mathrm{MoNi}+0.5 \mathrm{~V}$ material. There is more uniform distribution of carbides and the presence of vanadium in the matrix. Coarse eutectic interdendritic rod-like continuous $\mathrm{M}_{7} \mathrm{C}_{3}$ carbides network in the gray tempered martensite matrix of $\mathrm{FB} \mathrm{Cr} 26 \mathrm{MoNi}$ material is more prone to easy crack propagation. Since, carbides are brittle, their continuous network would provide a preferred path for fast crack growth. Tempered martensite matrix holds carbides less firmly which results in splitting of carbides from the surface. More uniform distribution of globular MC type carbides and chunk like $\mathrm{M}_{7} \mathrm{C}_{3}$ carbides in the martensite matrix of $\mathrm{FB} \mathrm{Cr} 26 \mathrm{MoNi}+0.5 \mathrm{~V}$ material is quite favorable for delaying the crack propagation. This type of distribution is studied and found to have a better combination of hardness and impact strength. Therefore, morphology of FB Cr26MoNi+0.5V material is highly stable as compared to that of FB Cr26MoNi material. Since, EDS analysis has shown that $\mathrm{MC}$ type carbide is vanadium carbide (VC) and $\mathrm{M}_{7} \mathrm{C}_{3}$ carbide is chromium carbide $\left(\mathrm{Cr}_{7} \mathrm{C}_{3}\right)$, VC precipitates with $2800 \mathrm{HV}$ hardness along with $\mathrm{M}_{7} \mathrm{C}_{3}$ precipitates with $1200 \sim 1800 \mathrm{HV}$ hardness induce more hardness in the matrix. Presence of vanadium in the matrix of cast iron material is reported to gives additional strengthening effect [4] which helps in delaying crack initiation and propagation.

\section{Hardness behavior}

Hardness was tested on samples from different cast iron blocks. A graph of 'Hardness Value' (HV) with 'Vanadium' content (wt. \%) was plotted and it is shown in Fig. 4. Hardness test result shows that the HCrCI grade, FB Cr26MoNi with vanadium content of $0.5 \mathrm{wt} . \%$ has achieved the highest hardness value. Vanadium addition, initially, would have led to precipitation of fine vanadium carbides (VC type) which favors martensitic transformation [8, 9, 10]. With vanadium 
addition, $\mathrm{M}_{7} \mathrm{C}_{3}$ type carbides are reported to restrict continuous needle like carbides precipitation to discontinuous and chunk like carbides. Higher hardness and higher affinity to carbon of $\mathrm{VC}$ as compared to $\mathrm{M}_{7} \mathrm{C}_{3}$ type carbides and the martensitic transformation might have imparted more hardness to the matrix of base material with $0.5 \mathrm{wt}$. \% V content. Higher vanadium content is found to stabilize austenite further and thereby reduces hardness value [7]. Therefore, Fig. 4 shows first increase and then decrease in hardness.
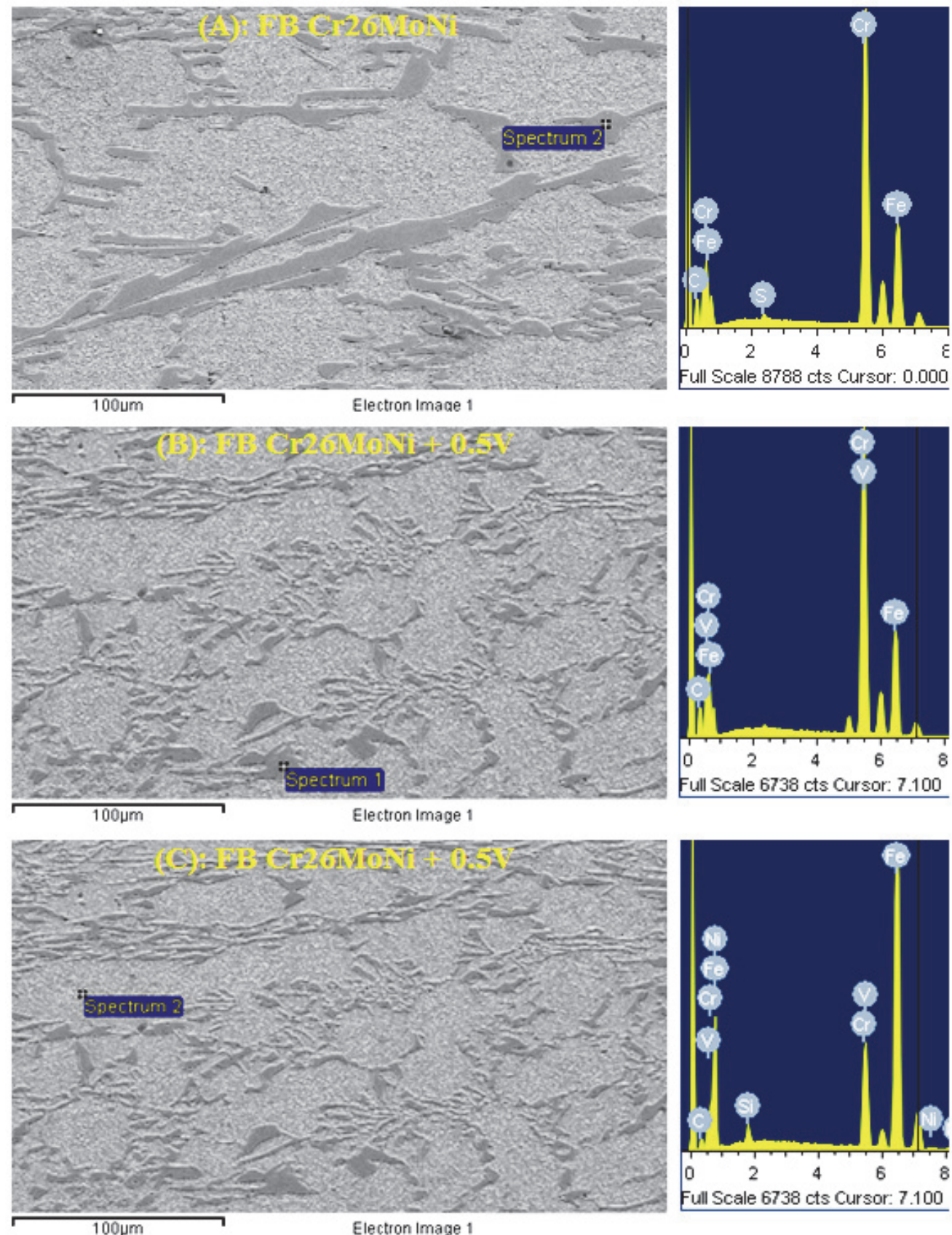

Figure 3: FESEM image and EDS spectrum of A) FB Cr26MoNi material precipitate, B) FB Cr26MoNi+0.5V material precipitate and C) $\mathrm{FB}$ Cr26MoNi+0.5V material matrix 


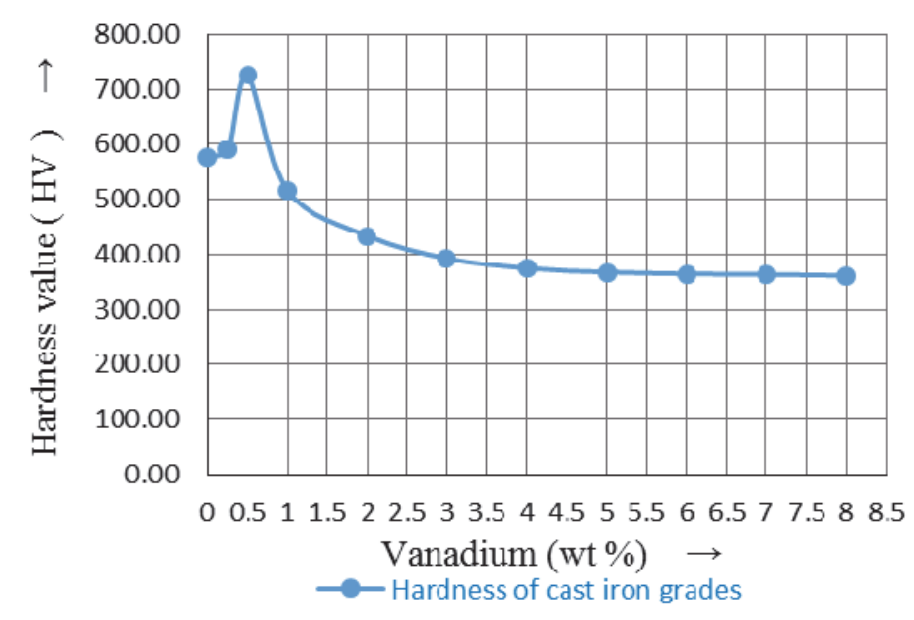

Figure 4: Hardness of cast iron grades with varying vanadium content

\section{Impact strength}

Since, $\mathrm{HCrCI}$ with 0.50 wt. $\%$ vanadium has the highest hardness, impact strength study was made for the $\mathrm{HCrCI}$ with vanadium content from 0.00 wt. $\%$ to 2.00 wt. $\% \mathrm{~V}$ range only. The Charpy impact test results (Fig. 5) show that the impact strength of the base material improves with increase in the vanadium content. Higher impact value with higher hardness is very much favorable for tube mill liner to ensure its higher service life. Vanadium forms VC type carbides first at higher temperature and act as heterogeneous nucleation nuclei for chromium carbide precipitation which leads to refinement of carbides and their improved distribution $[11,12,13,14]$. These morphological changes are observed to improve the impact strength of the cast iron grades. Therefore, it is found that the $\mathrm{HCrCI}$ with $0.5 \mathrm{wt} \%$ vanadium has the well suited combination of hardness and toughness properties for the parts experiencing impact and wear actions simultaneously.

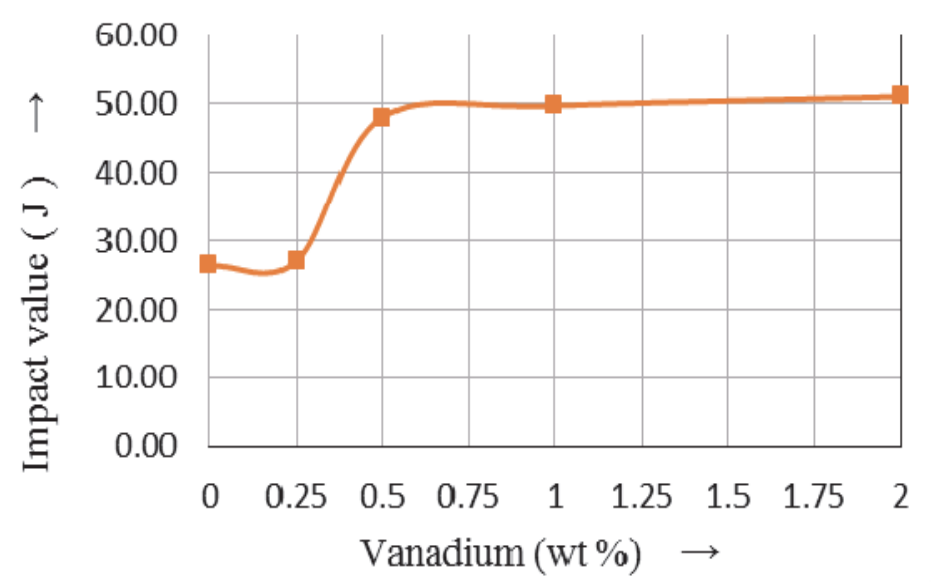

Figure 5: Impact strength of cast iron grades with varying vanadium content

\section{Abrasion wear testing}

The $\mathrm{HCrCI}$ with $0.5 \%$ vanadium content is found to have the highest combination of hardness and impact strength. Therefore, an exclusive abrasive wear study of the base material (FB Cr26MoNi) and the developed material (FB $\mathrm{Cr} 26 \mathrm{MoNi}+0.5 \mathrm{~V}$ ) was made as per the standard ASTM G 65. The volume loss of materials was calculated as per the Eqn. (2).

$$
\text { Volume loss, } \mathrm{mm}^{3}=\frac{\text { Mass loss }(\mathrm{g})}{\text { Density }\left(\mathrm{g} / \mathrm{cm}^{3}\right)} \times 1000
$$


The test results are given in Tab. 2. The results show that the $\mathrm{HCrCI}$ grade, $\mathrm{FB} \mathrm{Cr} 26 \mathrm{MoNi}$ with $0.5 \mathrm{wt} \%$ vanadium addition is comparatively a higher wear resistant alloy which is more suitable for wear resistance application. The wear resistance of the developed cast iron grade ( $\mathrm{FB} \mathrm{Cr} 26 \mathrm{MoNi}+0.5 \mathrm{~V}$ ) was calculated as the ratio of volume loss of the reference material (FB $\mathrm{Cr} 26 \mathrm{MoNi}$ ) to the volume loss of that material. The average abrasive wear resistance of $\mathrm{FB}$ $\mathrm{Cr} 26 \mathrm{MoNi}+0.5 \mathrm{~V}$ material as compared to $\mathrm{FB} \mathrm{Cr} 26 \mathrm{MoNi}$ material is 2.33 . This shows that FB Cr26MoNi $+0.5 \mathrm{~V}$ material has higher wear resistance and it is more suitable for liner applications in coal pulverizers. Therefore, the comparative wear study of prototype liners of these materials for 2,667 hours was made by installing them in a coal pulverizing tube mill. The average wear out thickness of the developed liner (FB Cr26MoNi +0.5V) and the normal liner (FB Cr26MoNi) were found to be $0.83 \mathrm{~mm}$ and $2.08 \mathrm{~mm}$, respectively. The above data shows a higher wear life for the cast iron grade, FB $\mathrm{Cr} 26 \mathrm{MoNi}+0.5 \mathrm{~V}$.

\begin{tabular}{|c|c|c|c|c|c|c|}
\hline Material: & \multicolumn{3}{|c|}{ FB Cr26MoNi } & \multicolumn{3}{|c|}{ FB Cr26MoNi $+0.5 \mathrm{~V}$} \\
\hline Sample No: & A11 & A12 & A13 & A3H1 & $\mathrm{A} 3 \mathrm{H} 2$ & A3H3 \\
\hline Test time, min: & 45 & 45 & 45 & 45 & 45 & 45 \\
\hline Initial mass, g: & 84.5123 & 84.7395 & 84.5744 & 86.8523 & 86.8457 & 81.5244 \\
\hline Final mass, g: & 84.1666 & 84.3957 & 84.1764 & 86.7301 & 86.6998 & 81.3267 \\
\hline Mass loss, g: & 0.3457 & 0.3438 & 0.3980 & 0.1222 & 0.1459 & 0.1977 \\
\hline Mass loss, mg/min: & 7.7 & 7.6 & 8.8 & 2.7 & 3.2 & 4.4 \\
\hline Volume loss, $\mathrm{mm}^{3}$ : & 46.2784 & 46.0241 & 53.2798 & 16.3588 & 19.5315 & 26.4659 \\
\hline $\begin{array}{l}\text { Volume loss per kg of erodent, } \\
\mathrm{mm}^{3} / \mathrm{Kg} \text { : }\end{array}$ & 9.3492 & 9.2978 & 10.7636 & 3.3048 & 3.9457 & 5.3466 \\
\hline $\begin{array}{l}\text { Average volume loss per } \mathrm{kg} \text { of } \\
\text { erodent, } \mathrm{mm}^{3} / \mathrm{Kg} \text { : }\end{array}$ & & 9.8035 & & & 4.1991 & \\
\hline
\end{tabular}

Table 2: Abrasive wear test result of the base material and the developed material

\section{CONCLUSIONS}

etailed study on the abrasion wear, mechanical behavior, microscopic examination and characterization of $\mathrm{HCrCI}$ and $\mathrm{HCrVCI}$ grades leads to the following major conclusions:

1. All grades of cast irons were cast using die casting method and chemical compositions were achieved successfully with homogeneous matrix in the respective casting blocks.

2. 0.5 wt. $\%$ vanadium addition to the base $\mathrm{HCrCI}$ grade $(\mathrm{FB} \mathrm{Cr} 26 \mathrm{MoNi})$ has refined the microstructure to form globular VC type carbides and chunk like $\mathrm{Cr}_{7} \mathrm{C}_{3}$ carbides distribution in the martensite matrix. This is quite favorable for improved life of liners in tube mills.

3. $\mathrm{HCrVCI}$ grade, $\mathrm{FB} \mathrm{Cr} 26 \mathrm{MoNi}+0.5 \mathrm{~V}$ has higher abrasion wear resistance and higher combination of hardness and impact strength as compared to the reference $\mathrm{HCrCI}$ grade, FB Cr26MoNi. Hence, the HCrCI with 0.5 wt. $\%$ vanadium addition is more promising with enhanced properties of hardness, impact toughness and higher abrasion wear resistance for tube mill liner application.

4. The study of prototype liners of the developed cast iron shows a higher service life as compared to the existing base material liners.

\section{ACKNOWLEDGEMENT} supporting this study. They acknowledge the officials at Surface Coating Department, BHEL, Corporate R\&D, Hyderabad for their support in carrying out the wear test of cast iron samples. They acknowledge the concerned 
officials at Quality Labs, BHEL Ramachandrapuram for the chemical analysis and officials at Heat Treatment Shop, BHEL, Ramchandrapuram for the heat treatment of cast iron blocks.

\section{REFERENCES}

[1] Zhi, X., Xing, J., Fu, H., Gao, Y. (2008). Effect of titanium on the as-cast microstructure of hypereutectic high chromium cast iron, J. Mater. Charact. 59, pp. 1221-1226. DOI: 10.1016/j.matchar.2007.10.010.

[2] Filipovic, M., Kamberovic, Z., Korac, M. (2013). Microstructure and mechanical properties of Fe-Cr-C-Nb white cast irons, J. Mater. Des. 47, pp. 41-48. DOI: 10.1016/j.matdes.2012.12.034.

[3] Xinhui, F., Lin, H., Qingde, Z. (1989) A Structural Study of High Chromium Cast Iron as a Grinding Ball Material, J. Met. Sci. Technol., 5, pp. 401-406.

[4] Sawamoto, A., Ogi, K., Matsuda, K. (1986). Solidification Structures of Fe-C-Cr-(V-Nb-W) Alloys, J. AFS Transactions, 72, pp. 403-416.

[5] Dodd, J., Parks, J. L. (1980). Factors Affecting the Production and Performance of Thick-Section High ChromiumMolybdenum Alloy Iron Castings, J. Metals Forum, 3 (1), pp. 3-12.

[6] Radulovic, M., Fiset, M., Peev, K., Tomovic, M. (1994). The Influence of Vanadium on Fracture Toughness and Abrasion Resistance in High Chromium White Cast Irons, J. Journal of Materials Science, 29, pp. 5085-5094.

[7] Keming, L., Fuming, W, Changrong, L., Liuyan, S. (2005). Influence of Vanadium on microstructure and Properties of Medium-chromium White Cast Iron, Available at: http://vanitec.org/technical-library/paper/influence-ofvanadium-on-microstructure-and-properties-of-medium-chromium-w.

[8] Yuwei, W., Wen S., (1989). The Effect of V in High Cr Cast Iron, J. Foundry, 5, pp. 9-12.

[9] Junyi, S., Xiangzhong, G., Enze, W. (1984). Study on High Chromium White Cast Iron Containing Vanadium with Martensite Matrix in the As-cast Condition, J. Journal of Xi'an Jiaotong University, 18(5), pp. 23-28.

[10] Yifu, Y., Tongxiang, F. (1995). Spheroidizing of Carbides of White Cast Iron, J. Modern Cast Iron, 3 pp. 28-32.

[11] Scandian, C., Boher, C., De Mello, J.D.B., Rézaï-Aria F., (2009). Effect of molybdenum and chromium contents in sliding wear of high-chromium white cast iron: the relationship between microstructure and wear, Wear, 267, pp. 401-408. DOI: $10.1016 /$ j.wear.2008.12.095

[12] Pierson, H.O., (1996). Handbook of refractory carbides and nitrides, 1st ed. Sandia National Laboratories, Available at:

file:///E:/Paper\%20published_to\%20be\%20published/ICON2018\%20Papers/Paper\%20submission_Frattura\%20e d\%20Integrita/References\%20HCrVWCI/Ref\%2013.pdf

[13] Xiang, C., Yanxiang, L., (2010). Effect of heat treatment on microstructure and mechanical properties of high boron white cast ,iron, J. Mater Sci Eng A, 528, pp. 770-775. DOI: 10.1016/j.msea.2007.10.009

[14] Xiaohui, Z., Jiandong, X., Yimin, G., (2008). Effect of heat treatment on microstructure and mechanical properties of a Ti-bearing hypereutectic high chromium white cast iron, Mater Sci Eng A, 487, pp. 171-179. DOI: $10.1016 /$ j.msea.2007.10.009

[15] Ogi, K., Matsubara, Y., Matsuda, K., (1982). Eutectic solidification of high chromium cast iron-mechanism of eutectic growth, AFS Transactions, 89, pp. 197-204. 